\title{
Atualização tecnológica em pequenas e médias empresas: proposta de roteiro para aquisição de sistemas integrados de gestão (ERP)
}

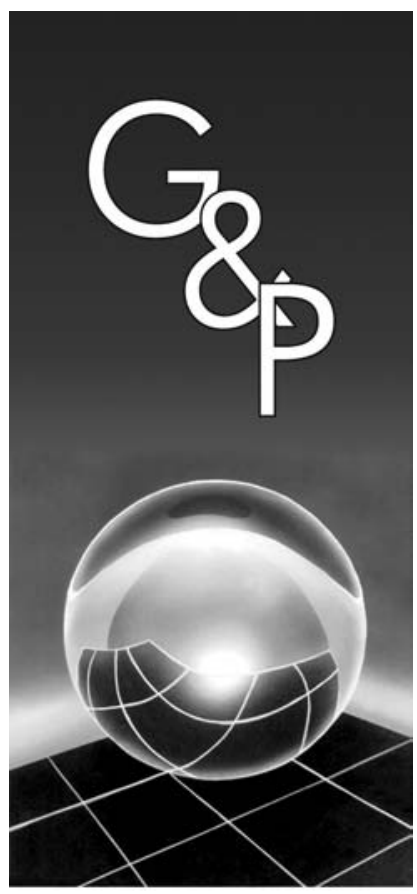

\author{
Juliana Veiga Mendes \\ Edmundo Escrivão Filho
}

Resumo

O objetivo principal do artigo é apresentar os resultados de uma pesquisa realizada na elaboração e validação de um roteiro ideal para a aquisição de sistemas integrados de gestão (ERP) adequados às características das pequenas e médias empresas (PME). O roteiro oferece uma visão geral das etapas a seguir na adoção do ERP e orienta não na escolha do sistema ou fornecedor, mas na necessidade de avaliar as adequações e impactos na mudança da organização. Essas mudanças não são secundárias ou periféricas à adoção do ERP; na verdade irão definir a potencialidade de operação do sistema e, conseqüentemente, a eficácia da aquisição. $O$ trabalho de campo foi realizado em duas etapas: na primeira etapa foram investigadas dez empresas, e aconteceu após a revisão bibliográfica sobre modelos de adoção de tecnologia da informação; esta etapa foi útil para ajustar os conceitos teóricos à realidade das PME. A segunda etapa aconteceu após a elaboração do roteiro ideal e teve o propósito de validá-lo em duas empresas. A pesquisa realizada tem limitações, porém os resultados são relevantes diante da escassez de literatura apropriada referente à adoção de ERP por PME. O modelo elaborado mostrou-se mais detalhado do que os procedimentos empresariais usados e, conseqüentemente, útil às PME em fase de atualização tecnológica com os ERP.

Palavras-chave: Sistemas integrados de gestão ERP. Pequenas e médias empresas.

\section{Introdução}

Nas últimas décadas, nota-se no meio acadêmico um discurso enfático, e muitas vezes repetitivo, acerca da necessidade das empresas pela busca de soluções que as capacitem a obterem ganhos em competitividade, permitindo assim uma atuação compatível com as exigências mundiais e a intensa concorrência instalada com a globalização dos mercados. Nessa busca por competitividade e melhoria no desempenho organizacional, uma das estratégias adotadas por diversas empresas consiste em focar seus esforços na adoção de novas tecnologias capazes de incrementar seu desempenho. A tecnologia adquirida de forma coerente com a estratégia e com os recursos organizacionais pode ser um parâmetro vital para assegurar níveis de competitividade compatíveis com os desafios empresariais da atualidade.

Para as pequenas e médias empresas (PME), a incorporação de recursos tecnológicos pode ser um fator de diferenciação, contribuindo, significativamente, para manter padrões de competitividade compatíveis com as grandes organizações, e pode constituir a diferença entre sobreviver e desaparecer, alerta Kruglianskas
(1996). No Brasil, a competitividade dessas organizações, especialmente daquelas pertencentes a cadeias produtivas nas quais se inserem grandes organizações, é essencial ao desenvolvimento do país. Com a globalização da economia, empresas de grande porte iniciaram a terceirização de boa parte de seu processo de produção, impondo que organizações menores passassem a integrar a mesma cadeia produtiva em que atuam, revelando assim a importância estratégica das pequenas organizações na competitividade das grandes organizações. A falta de qualidade, confiabilidade ou preço competitivo, em quaisquer dos elos desta cadeia, pode comprometer a competitividade de todas as empresas que dela fazem parte.

Visando responder a essas pressões do mercado, e buscando a adoção de soluções inovadoras que suportem a gestão de seus processos de negócio, as PME são cada vez mais impulsionadas a adquirirem soluções tecnológicas, algumas antes disponíveis e viáveis apenas para grandes corporações. Porém, é inconseqüente desconsiderar as características particulares e peculiares desse 
segmento, principalmente a característica referente à disponibilidade de recursos para investimento em tecnologia. Diante dessas especificidades, Firmino (2003) faz uma observação importante ao afirmar que, para a incorporação de recursos tecnológicos pelas PME, espera-se uma adaptação do dirigente à tecnologia e não o inverso.

A relação positiva entre tecnologia, competitividade e vantagem competitiva, ainda é difícil de ser estabelecida, mas no âmbito empresarial as vantagens, facilidades e imposições de uma economia baseada no uso intenso de recursos tecnológicos parecem conduzir as empresas a um caminho sem volta. Muitos autores como McGee e Pruzak (1997) reconhecem que o gerenciamento da informação é fator de competitividade, reiterando assim, a crença de que a tecnologia pode solucionar diversos problemas enfrentados pelas empresas, tecnologia cuja importância é admitida pela maioria dos executivos, embora muitas de suas experiências nesta área sejam marcadas pela frustração.

Considerando uma relação positiva entre tecnologia e competitividade, Silva et al. (1998) afirmam que os sistemas integrados de gestão ou sistemas ERP podem representar vantagem competitiva para as empresas, pois as apóiam na obtenção de maior agilidade, melhor controle, maior confiabilidade e fácil acesso às informações.

Segundo Huang et al. (2003), os ERP emergiram como uma tecnologia desenvolvida para suportar as atividades de reengenharia dos processos de negócio, com o objetivo de garantir maior eficiência ao fluxo de trabalho (workflow) dentro da empresa. O ERP integra os dados processados em várias áreas funcionais da empresa, garantindo maior agilidade e possibilitando um tempo de resposta mais rápido. Conseqüentemente, o ERP pode contribuir positivamente para melhorar a comunicação interna das unidades de negócio da organização e a comunicação entre essas unidades.

Por definição, esses sistemas, como observa Wood Jr. (1999), são capazes de integrar toda a gestão da empresa, agilizando o processo de tomada de decisão. Podem ser aplicados com adaptações a qualquer empresa, permitindo o seu monitoramento em tempo real. As expectativas sobre seu impacto são enormes e os investimentos que implicam são gigantescos.

Os ERP foram, inicialmente, desenvolvidos para grandes empresas, tendo sido adquiridos por uma infinidade delas (HUANG et al., 2003), principalmente no fim da década de 90. Nesse período, o furor em torno desses sistemas, insuflado por agressivas campanhas de marketing promovidas por empresas de consultoria e fornecedoras de sistemas levou várias empresas, principalmente aquelas de grande porte, a adquiri-los em clima de urgência sem uma análise cuidadosa sobre os riscos associados, sendo motivadas, principalmente, pelos ajustes aos sistemas de informação demandados pelo bug do milênio. Os ERP tornaram-se um representante da abordagem "melhores práticas" (best practice) e uma obsessão para os empresários em geral. Transcorrido esse período e saturado o segmento das grandes corporações, as fornecedoras de ERP e as consultorias especializadas se voltaram para o segmento das PME, lançando estratégias de atuação diferenciadas.

Os ERP são um dos principais sistemas de informação da atualidade e sua importância se dá ao fato de ser uma ferramenta de gestão empresarial amplamente reconhecida. No entanto, sua adoção requer investimentos vultosos, e sua implantação exige o desembolso de quantias significativas com consultorias especializadas. Assim, torna-se relevante um roteiro para apoiar as atividades gerenciais, especialmente das pequenas e médias empresas, nesse processo de adoção e implantação de ERP. A utilização do roteiro pode ser fundamental para viabilizar a aquisição desses sistemas pelas PME. Como PME serão consideradas nesse trabalho empresas classificadas segundo um critério explicitado adiante. Além disso, os roteiros e metodologias desenvolvidos são normalmente orientados para grandes empresas, como pode ser observado pela discussão de Siau (2004), e pela proposta de Zwicker e Souza (2003).

Para apresentar o processo de desenvolvimento do roteiro, esse artigo está estruturado em cinco seções, além dessa contextualização inicial. A próxima seção apresenta o conceito referente aos ERP, destacando aspectos relacionados à implantação, vantagens e dificuldades com sua adoção. Na terceira seção, explicita-se o processo de desenvolvimento do roteiro, destacando a base teórica para sua elaboração e o trabalho de campo realizado em PME usuárias de ERP, com o objetivo de avaliar as práticas e os conhecimentos desse segmento empresarial no que se refere ao processo de adoção desses sistemas. A quarta seção apresenta uma descrição detalhada do roteiro ideal, e na quinta seção é descrito o estudo de dois casos de aplicação do roteiro e os resultados obtidos. Concluindo o artigo, a sexta seção apresenta as considerações finais sobre o uso e aplicação do roteiro no ambiente das PME.

\section{Sistemas integrados de gestão - ERP: o conceito}

A revisão da literatura sobre ERP permite observar que os conceitos sobre esses sistemas estão fundamentados na abrangência das diversas áreas e funções empresariais fornecidas ao gestor, conforme pode ser observado nos dois parágrafos a seguir.

Corrêa et al. (1997) definem os sistemas ERP como sendo constituídos por vários módulos integrados que atendem às necessidades de informação de apoio para 
tomada de decisão em todos os setores da empresa integrados entre si, a partir de uma base de dados única e não redundante.

Concentrando sua definição na abrangência e na visão de processos, Tarn et al. (2002) definem os ERP como sendo sistemas constituídos por uma série de módulos, como por exemplo: contabilidade, distribuição, marketing e vendas, manufatura, recursos humanos, entre outros, sendo todos os módulos suportados por uma base de dados única. Os autores destacam a orientação dos ERP aos processos de negócio e não às áreas funcionais tradicionais da empresa, e definem que o maior objetivo desses sistemas é unir os vários departamentos da organização através de um único sistema de informação, possibilitando o fluxo de informação integrado, capaz de fornecer os dados e informações a todos componentes da organização.

Além da integração interna, recentemente muitas publicações acadêmicas vêm destacando a evolução do papel dos sistemas ERP nas atividades de integração externa ao suportar as atividades de SCM (supply chain management) e de CRM (customer relationship management), como pode ser observado em Tarn et al. (2002), Huang et al. (2003), Lee et al. (2003), Gupta et al. (2004), Siau (2004), Siau e Tian (2004), Chuang e Shaw (2005) e Wang e Zhang (2005).

Ao que parece, a integração proposta pelos ERP tende a extrapolar os limites organizacionais e a penetrar na cadeia de empresas. Resta, porém, identificar o quanto isto vem realmente acontecendo no âmbito empresarial e o quanto não está restrito ao agressivo marketing de empresas fornecedoras e implantadoras de soluções dessa natureza.

São, portanto, sistemas que procuram ser extensivos a todas as possíveis atividades realizadas por uma organização, visando atender ampla gama de atividades empresariais. A idéia contida nos ERP é desenvolver o máximo de funcionalidades, para se atender ao maior número possível de atividades dentro da cadeia de valor. As funcionalidades, segundo Souza (2000), consistem no conjunto total de funções embutidas em um sistema integrado, com suas características e diferentes possibilidades de uso. Os módulos do sistema correspondem aos menores conjuntos de funções que podem ser adquiridos e implementados separadamente. Essa divisão em módulos permite que a empresa implante apenas aqueles que sejam de seu interesse, e que desejando implementar todo o sistema, possa fazê-lo em etapas, para simplificar o processo.

A implantação é uma etapa muito complexa e compreende um amplo processo de mudança organizacional, que provoca impactos sobre o modelo de gestão, a arquitetura organizacional, o estilo gerencial, os processos de negócios, e principalmente, sobre as pessoas (WOOD
Jr., 1999). Deve envolver uma equipe multidisciplinar composta por especialistas em tecnologia da informação, analistas de negócios e consultores capacitados em redesenho de processos. Corrêa (1998) alerta para a importância do comprometimento da alta direção da empresa, que precisa ter uma visão clara e compartilhada da situação futura, e uma compreensão da implantação como um projeto de mudança organizacional.

As vantagens com a adoção desses sistemas são inúmeras: registro das informações na origem, diminuição de retrabalho e duplicidade de informações, disponibilidade de informações para toda a empresa, maior agilidade e integração dos processos, e maior interação entre a organização e as entidades externas - fornecedores, clientes e mercado, entre outras, afirmam Silva et al. (1998). Para as PME, a grande vantagem citada por Taurion (1999) reside na oportunidade de subir na escala tecnológica, pela aquisição do sistema e do hardware para suportá-lo. $\mathrm{Na}$ verdade, os ERP representam a criação de uma infraestrutura de aplicativos fundamentada na tecnologia do sistema escolhido. As decisões futuras relacionadas à modelagem dos processos de negócio e à implantação de novas soluções sistêmicas deverão considerar a tecnologia estabelecida pelo sistema (CUNHA, 1998).

Contudo, as dificuldades encontradas num projeto de adoção de ERP também são numerosas. Dentre elas, podem-se destacar as profundas alterações nos processos empresariais, a complexidade das tarefas de customização, o alto custo relacionado às atividades de consultoria e treinamento, alterações constantes e gerenciamento de versões (SOUZA; ZWICKER, 2000; STAMFORD, 2000; TARN et al., 2002). Mesmo após sua implantação, o sistema se mantém em evolução contínua para refletir os processos da empresa, e muitas alterações podem ser consideradas como novas implementações (DAVENPORT, 1998).

Segundo Tarn et al. (2002), o grande desafio, para as organizações em geral, consiste em como obter vantagem competitiva com as informações disponibilizadas pelo ERP.

\section{Desenvolvimento do roteiro ideal}

Roteiro pode ser entendido como uma " [...] descrição minuciosa, metódica e escrita da indicação de direção e dos principais passos que se deve conhecer." (adaptado de FERREIRA, 1975, p. 1249) para ir de um lugar (ou situação) atual a outro (a) desejado (a). O roteiro desenvolvido recebeu o nome de roteiro ideal inspirado no modelo ideal (GREMBA; MYERS, 1998) desenvolvido pelo SEI (software engineering institute) para acompanhar as atividades relacionadas ao desenvolvimento de software. A palavra 'ideal' teve também o propósito de reproduzir o uso de Max Weber (WEBER, 1991); tipo 
ideal é uma construção metodológica, racional e lógica para orientar o exame da situação particular. Portanto, roteiro ideal não tem o sentido de orientar a escolha do melhor sistema ou do melhor fornecedor, mas ser uma descrição de acompanhamento sistemático do gestor das PME dos passos principais na adoção e implantação do ERP. O modelo ideal é apresentado na seção 4.

$\mathrm{O}$ desenvolvimento do roteiro ideal teve como referência teórica dois modelos para adoção de tecnologia da informação e um modelo orientado especificamente para a adoção de sistemas ERP, sendo esses modelos apresentados a seguir. $\mathrm{O}$ estudo desses modelos foi utilizado como base para identificação das atividades relevantes consideradas no processo de adoção de recursos da tecnologia da informação.

\subsection{Modelos teóricos para adoção de tecnologia da informação (TI)}

Com a percepção de que a inovação tecnológica pode trazer mudanças profundas para as empresas, Cooper e Zmud (1990) apresentam um modelo construído a partir da literatura a respeito de mudança organizacional, inovação e difusão tecnológica. Este modelo propõe seis estágios para adoção de TI:

a) iniciação: são examinados os problemas organizacionais e as possibilidades da TI até que se localize uma possibilidade de aplicação dessa tecnologia como solução;

b) adoção: são realizadas as negociações entre os interessados na empresa e são aprovados o projeto de implementação e os investimentos necessários;

c) adaptação: são instalados os processos através dos quais a aplicação da TI será desenvolvida; são revistos os procedimentos organizacionais e treinados os usuários;

d) aceitação: os usuários são induzidos a se comprometerem com a aplicação da TI;

e) rotinização: o uso da TI é encorajado como uma atividade do dia-a-dia; e

f) incorporação: amplia-se a eficácia e a eficiência organizacionais pelo uso da tecnologia.

Outra alternativa utilizada como referência na adoção de tecnologia é o denominado modelo ideal (GREMBA; MYERS, 1998), desenvolvido pela SEI (software engineering institute). Este modelo pressupõe passos sistemáticos e de melhoria contínua propostos, em sua concepção original, para o desenvolvimento de software. Porém, tais passos podem ser adaptados e utilizados pelas empresas na adoção e incorporação de novas tecnologias e em atividades de aperfeiçoamento crescente. Ele engloba cinco fases sintetizadas a seguir:

a) inicialização: fase em que se define o estímulo à melhoria; b) diagnóstico: visa caracterizar o estado atual e futuro (desejado) da organização;

c) estabelecimento de diretrizes: propõe a definição das prioridades para as alterações, o estabelecimento de uma estratégia para a realização do trabalho;

d) ação: visa criar a solução que atenda às necessidades organizacionais identificadas; ou seja, validar a solução criada; e

e) lições: as lições são coletadas, analisadas e documentadas.

Focando os ERP, Zwicker e Souza (2003) propõem um modelo para adoção, denominado Ciclo de Vida de Sistemas ERP, constituído pelas etapas a seguir:

a) decisão e seleção: ocorrem segundo um procedimento interativo, através do qual a organização toma conhecimento das diversas soluções disponíveis e seleciona uma delas, considerando aspectos como a aderência das funcionalidades do sistema às necessidades da empresa, a arquitetura técnica do produto, os custos, o serviço pós-venda, a saúde financeira do fornecedor, e também as alternativas para a realização dos serviços de implementação;

b) implementação: etapa crítica em que os módulos são colocados em funcionamento e o sistema inicia o processamento das transações empresariais; $\mathrm{e}$

c) utilização: alimenta a implementação, considerando-se que, no momento em que esta ocorre, não são conhecidas todas as possibilidades de uso do sistema.

Após estudo desses modelos, obteve-se a fundamentação teórica para a construção do roteiro ideal. Entre os modelos consultados, foram observados consensos nas seguintes etapas: diagnóstico, onde se faz uma caracterização dos problemas da empresa; seleção, onde é prospectada a melhor solução existente no mercado; implementação, essa etapa consiste na instalação técnica do sistema no hardware da empresa; e utilização, onde a tecnologia é incorporada à rotina empresarial. Essas etapas, nos modelos analisados, podem estar explícitas ou embutidas em outras etapas e foram consideradas, no âmbito desse trabalho, como fundamentais para a adoção de qualquer recurso de TI. Essas observações foram estudadas e contextualizadas à luz do conceito de sistemas ERP, das características das PME e do trabalho de campo, apresentado na seqüência. Após todas essas considerações foi possível propor então o roteiro ideal, descrito posteriormente à apresentação do trabalho de campo.

\subsection{Descrição do trabalho de campo}

A primeira etapa do trabalho de campo foi conduzida em uma amostra com dez PME e teve a natureza de pesquisa exploratória, a fim de fornecer alguns referenciais empíricos aos modelos teóricos apresentados na seção anterior. Para classificar as empresas, muitos 
são os critérios encontrados na literatura. Existem critérios qualitativos e quantitativos; os primeiros podem ser ilustrados pelo critério do comportamento e atitude da alta direção; e os segundos, pelo critério do número de funcionários ou pelo faturamento. No contexto do objeto de estudo desse artigo, os sistemas integrados, optou-se por observar a classificação utilizada pelas empresas que desenvolvem e comercializam esses sistemas. Uma publicação da revista Computerworld (COMPUTERWORLD, 1999) procurou sistematizar as estratégias adotadas pelas empresas fornecedoras de sistemas integrados e os mercados alvos. Assim, esta pesquisa adotou um critério de classificação de empresas adaptado aos utilizados por várias empresas fornecedoras de sistemas integrados, conforme apresentado no Quadro 1.

A amostra pode ser classificada como não-probabilística, segundo Corrêa e Dias (1998), até certo ponto arbitrária, uma vez que o objetivo não é a generalização estatística, mas analítica das conclusões. A amostra estudada foi elaborada com empresas que, supostamente, foram referências em relação à aquisição de sistemas integrados, por serem casos de pioneirismo e sucesso no quesito implantação. Portanto, a seleção das empresas foi por conveniência obedecendo aos seguintes critérios: empresas que haviam implantado sistemas integrados; empresas pertencentes a diferentes ramos de atividades; acesso e disponibilidade; estar situada na grande São Paulo; e ser classificada como PME, de acordo com critério no Quadro 1.

A partir daí, montou-se a amostra com dez empresas, que permitiu analisar diferentes setores industriais, como pode ser observado no Quadro 2. As empresas analisadas possuíam faturamento anual entre $\mathrm{R} \$ 8$ e 40 milhões

Quadro 1. Classificação do porte de empresas adotado nesta pesquisa.

\begin{tabular}{cc}
\hline Classificação & Faturamento anual $(\mathbf{R} \$)$ \\
\hline Pequena & 5 a 30 milhões \\
Média & 30 a 100 milhões \\
Grande & Acima de 100 milhões \\
\hline
\end{tabular}

Quadro 2. Ramo de atividades das empresas estudadas.

\begin{tabular}{ccc}
\hline Setor industrial & Ramo de atividade & $\mathbf{N}^{\circ}$ de empresas \\
\hline Indústria & Químico & 1 \\
& Plástico & 3 \\
& Eletrônico & 1 \\
Serviço & Metalurgia & 2 \\
& Transporte & 1 \\
& Consórcio & 1 \\
Total & Locação & 1 \\
\hline
\end{tabular}

de reais, podendo, portanto, serem consideradas PME, segundo o critério adotado. A coleta das informações ocorreu por meio de entrevistas semi-estruturadas, realizadas com o auxílio de um roteiro. Em todas as empresas estudadas, a entrevista foi realizada com o profissional da área de informática. Em geral, como são PME, esse profissional é, muitas vezes, o responsável pela área tecnológica da empresa, possui um cargo de gerência e durante a implantação do sistema integrado era o gerente do projeto responsável. A análise dessas informações permitiu tecer as considerações sintetizadas nos parágrafos a seguir sobre experiências empresariais na adoção de sistemas integrados em PME.

Os motivos para as empresas adotarem os sistemas integrados: o modismo empresarial; o bug do milênio; a integração entre as diversas áreas da empresa; e a garantia de confiabilidade nas informações obtidas através da base de dados única. O processo de seleção desses sistemas foi norteado pelo custo da solução a ser adotada. Quesitos como aderências da empresa às funcionalidades e aos processos do sistema são analisados em segundo plano, sendo que, entre as entrevistadas, somente uma empresa realizou a análise de aderência.

As principais barreiras e dificuldades enfrentadas pelas PME estão relacionadas: ao planejamento inadequado do projeto de implantação; à equipe de implantação contratada inexperiente; à resistência dos funcionários ao sistema e aos impactos organizacionais que não são avaliados previamente pelas empresas. Como resultados obtidos com a adoção do sistema, as PME mencionaram: a evolução da base tecnológica; a integração entre as áreas através do sistema; o impacto no controle e gestão da empresa, através de informações acuradas e sem redundância; e o impacto na administração de recursos humanos. Para o segmento empresarial em questão, um quesito relevante citado para a implantação dos sistemas integrados consiste na opção por soluções que permitam a condução da implantação com recursos próprios, necessitando pequeno auxílio e envolvimento de empresas de consultoria especializadas no assunto.

Diante das informações obtidas nesta primeira fase do trabalho de campo, evidenciaram-se as suspeitas iniciais, de que as PME, não possuindo recursos financeiros para contratação de serviços e mão-de-obra especializados, não realizam uma análise adequada que precede à adoção desses sistemas. Após a aquisição, iniciam a implantação sem um gerenciamento adequado e experiente, comprometendo os benefícios a serem obtidos, não explorando, assim, todas as potencialidades possíveis da gestão com uso dos sistemas integrados.

Com essas observações empíricas e a análise dos conceitos teóricos de três modelos, foi desenvolvido o roteiro ideal, que tem como objetivo suportar todas as etapas inerentes ao processo de adoção de sistemas inte- 
grados. Como o foco do roteiro são as PME, que optam por adquirir sistemas cuja implantação possa ser realizada com recursos próprios, o roteiro estabelece uma linguagem clara e simples, onde cada etapa está especificada de forma direta e concisa, e os resultados esperados após cada etapa também estão especificados.

\section{Descrição do roteiro ideal}

O uso do roteiro não tem como objetivo orientar a aquisição na escolha do melhor sistema ou fornecedor, mas sim guiar a reflexão e as decisões dos gestores das PME referentes à reflexão sobre a adoção de sistemas integrados, conscientizando para a necessidade de passos sistemáticos e para a análise das conseqüências da mudança organizacional. O roteiro ideal compreende cinco partes principais, ilustradas pela Figura 1, e apresentadas a seguir:

a) parte A - avaliação sobre a necessidade de ERP: consiste em analisar a situação atual das PME e em identificar como o sistema pode contribuir para solucionar seus problemas organizacionais;

b) parte B - seleção e adequação: comporta a análise e verificação da adequação de funcionalidades dos sistemas integrados às PME;

c) parte $\mathbf{C}$ - implantação: compreende desde o planejamento das atividades que precedem a implantação até a consumação da mesma;

d) parte D - conscientização e treinamento: consiste na realização de palestras, seminários e atividades de conscientização para os membros organizacionais e de treinamento operacional e gerencial; e

e) parte E - utilização: abrange as etapas de uso do sistema e a identificação de alterações para se atender a mudanças nas regras de negócio.

Essa apresentação inicial do roteiro ideal em cinco partes amplas é sucedida por um detalhamento em etapas pormenorizadas, visualizadas na Figura 2, na qual são representadas todas as atividades do roteiro.

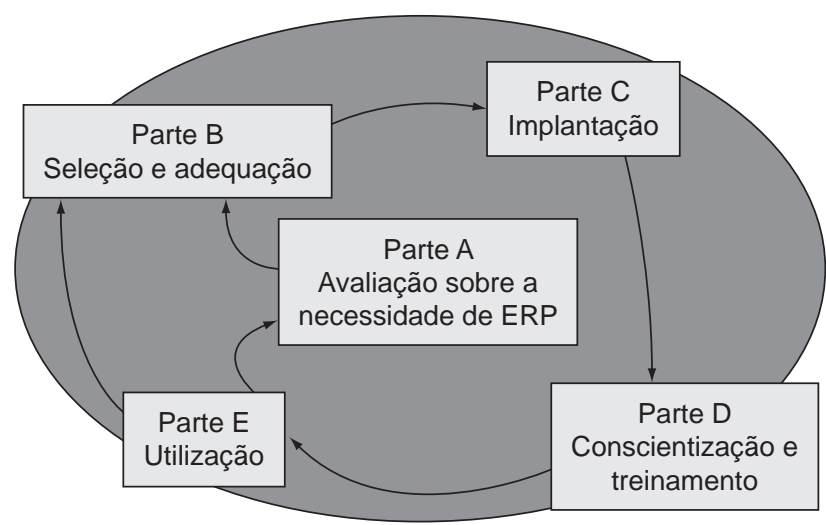

Figura 1. Visão dinâmica do roteiro ideal.
A aplicação do roteiro deve ficar sob a responsabilidade de um funcionário da alta administração, estendendo-se às áreas de informática e de negócios. As duas primeiras partes do roteiro demandam o envolvimento dos níveis mais altos de direção da empresa, pois se referem à tomada de decisões sobre a adoção de um sistema com impactos organizacionais. A participação da alta administração durante todas as partes previstas pelo roteiro ideal é fator vital para garantir o sucesso sob o aspecto técnico e organizacional, da adoção do sistema integrado. Os parágrafos seguintes discutem o roteiro de forma detalhada, apresentando as etapas que compõem suas cinco partes principais.

A parte A, denominada Avaliação sobre a necessidade de ERP, tem como objetivo auxiliar a empresa a conduzir uma análise interna sobre sua situação atual, identificando problemas, pontos críticos e analisando qual a contribuição do sistema para as soluções dos problemas organizacionais. Engloba também a análise conceitual sobre sistemas integrados. O detalhamento da parte A é realizado em três etapas:

a) etapa 1 - análise da situação atual: reflete e discute sobre os pontos fortes e fracos da empresa;

b) etapa 2 - análise conceitual do ERP: estudo imparcial sobre esses sistemas, sem focar uma solução específica. Não é aconselhável, nesse momento, estabelecer contato com empresas de consultoria; e

c) etapa 3 - análise do ERP como solução: confronto, em termos conceituais e genéricos, do sistema com os pontos fortes e fracos da empresa.

A realização das etapas 1, 2 e 3 conclui a aplicação da parte A, e como resultado espera-se que as PME tenham realizado análise crítica de suas condições atuais, identificadas as vantagens e problemas relacionados ao sistema integrado e colhidos os subsídios para analisar como o sistema contribui para a solução de seus problemas. Caso a empresa conclua que o sistema integrado não é a solução adequada, finaliza-se a aplicação do roteiro Ideal. Caso contrário, prossegue-se a aplicação do roteiro, dando-se início à parte $\mathrm{B}$.

Com a parte B, seleção e adequação, inicia-se o relacionamento com os fornecedores de sistemas integrados, através de visitas, reuniões e apresentações. Os objetivos específicos deste momento são: analisar as soluções disponíveis no mercado, e selecionar aquelas adequadas às particularidades e especificidades da empresa. Ela está detalhada em quatro etapas:

a) etapa 4 - análise dos processos da empresa: realiza-se a revisão dos processos com o intuito de avaliar a necessidade de customizações, adaptações e modificações no sistema;

b) etapa 5 - seleção do sistema: análise dos sistemas disponíveis no mercado através da avaliação de suas características técnicas (funcionalidades e recursos 


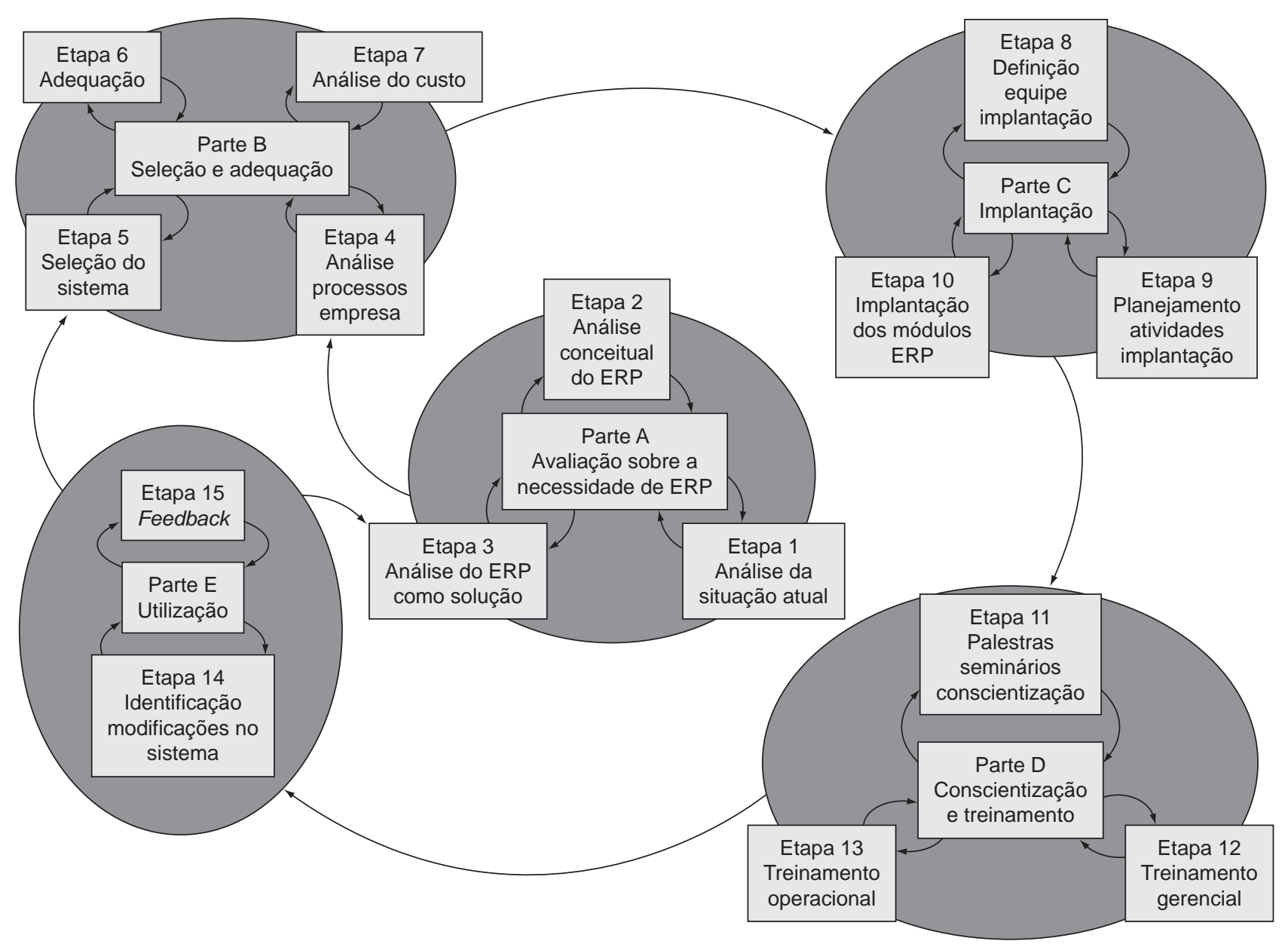

Figura 2. Visão detalhada do roteiro ideal.

tecnológicos necessários) e dos processos implementados;

c) etapa 6 - adequação: comparação entre as funcionalidades e processos do sistema e as necessidades organizacionais; e

d) etapa 7 - análise de custo: devem ser identificados os seguintes itens de custo que envolvem os sistemas integrados: customizações necessárias, mão-deobra especializada para implantação e treinamento, investimento em hardware, e o contrato de manutenção após a implantação.

Ao concluir a parte B do roteiro ideal, a empresa solicita ao fornecedor a elaboração de um contrato no qual estejam definidas as funcionalidades do sistema, o tempo total de implantação, os serviços de suporte e os processos de manutenção e atualização de suas versões, a qualidade da documentação, e a descrição dos elementos necessários para manter o sistema. Também devem ser previstas, neste contrato, as consequiências de sua rescisão e do não cumprimento de suas cláusulas.

Os objetivos da parte $\mathbf{C}$, Implantação do sistema integrado, são sintetizados em: planejar as atividades de implantação, e gerenciar a execução destas atividades.
Corresponde ao ponto crítico do projeto, e sua execução está detalhada em três etapas:

a) etapa 8 - definição da equipe de implantação: constituída por funcionários experientes tecnicamente em implantação de sistemas e no negócio da empresa. Deve-se envolver o menor número possível de funcionários externos à empresa, devido ao custo elevado desses profissionais;

b) etapa 9 - planejamento das atividades de implantação: o plano de implantação deve estabelecer escopo do projeto e o tempo necessário para a execução. Serão definidos: os módulos a serem implantados; a ordem de implantação; a atribuição de responsabilidades e planos de contingência; e

c) etapa 10 - implantação dos módulos do sistema: consiste na parametrização e/ou customizações, de acordo com a adequação prevista na parte $\mathrm{B}$, do roteiro ideal, para que os módulos possam ser colocados em funcionamento e utilizados pela empresa. O equipamento necessário deverá estar devidamente instalado e funcionando corretamente.

A parte $D$, conscientização e treinamento, têm como meta reduzir a resistência e esclarecer as mudanças orga- 
nizacionais introduzidas na empresa. São três as etapas que a constituem:

a) etapa 11 - palestras e seminários de conscientização: esclarecimento sobre o sistema, as mudanças introduzidas, a importância organizacional, implicações sobre má utilização, e relevância do papel dos envolvidos;

b) etapa 12 - treinamento gerencial: orientados para a alta administração e o corpo gerencial, focando aspectos e possibilidades gerenciais do sistema e não características operacionais; e

c) etapa 13 - treinamento operacional: realizado por área da empresa, focando os módulos específicos. Deve esclarecer sobre a importância de não estabelecer controles paralelos, em conseqüência dos erros, mas aperfeiçoar constantemente o sistema e a relevância de informações atualizadas do sistema.

A comunicação durante a aplicação do roteiro sobre as modificações que estão ocorrendo, deve ser constante e processar-se de acordo com a linguagem de negócio da empresa e não de forma técnica. Os trabalhos de conscientização e treinamento são fundamentais para a segurança dos funcionários em relação ao sistema adotado, e para que todos na empresa estejam sintonizados com a realidade impressa no sistema. Tais atividades não devem ser abandonadas após a implantação da solução, precisam de continuidade para que sejam atendidos novos funcionários que terão também que lidar com o sistema.

A parte $\mathbf{E}$ do roteiro, denominada utilização, consiste na fase de uso do sistema ERP. Tais sistemas são soluções que exigem melhorias contínuas e atividades sistemáticas de treinamento e conscientização, independentemente da frequiência das mudanças. Assim, o objetivo dessa última etapa é identificar, após um período de uso, as necessidades de modificações a serem realizadas no sistema para que ele se mantenha em conformidade com a empresa. É detalhada em duas etapas:

a) etapa 14 - identificação de modificações no sistema: com o passar do tempo as regras de negócio da empresa vão sofrendo modificações e atualizações. Essas modificações induzem a alterações nos processos, e conseqüentemente, no ERP e,

b) etapa 15 - feedback: as modificações necessárias para atender as mudanças nas regras de negócio da empresa podem ser simples ou podem exigir novos desenvolvimentos, induzindo a nova aplicação do roteiro.

A realização da parte $E$ do roteiro não significa o fim de uma atividade sistemática, reflexiva e deliberada como é o propósito do roteiro. Espera-se que o roteiro seja utilizado repetidas vezes devido a diversas razões: a implantação parcial em algumas áreas da empresa deve acionar o uso do roteiro em uma decisão de aumentar o escopo do sistema; atualizações tecnológicas do sistema pelo fornecedor podem vir a exigir nova rodada de análise dos passos; mudanças na definição de negócios da empresa podem impor alterações no sistema e um exame cuidadoso das necessidades do ERP; expansão da empresa em volume ou diversificação impõe mudanças organizacionais, como adoção de processos de negócio ou estruturas divisionais, que acionam o uso do roteiro.

\section{Aplicação do roteiro ideal}

O estudo de casos de aplicação do roteiro ideal teve como propósito avaliar sua viabilidade e adequação para o segmento das PME. O longo tempo necessário para a execução de todas as partes previstas pelo roteiro inviabilizou sua aplicação completa como atividade de pesquisa acadêmica. Diante desta restrição, o roteiro foi utilizado posteriormente à implantação dos sistemas integrados nas PME estudadas, resgatando as informações pertinentes ao processo de adoção.

Seguindo as partes e as etapas previstas pelo roteiro, as PME foram questionadas sobre como conduziram a adoção desses sistemas. Tais informações foram analisadas à luz das etapas do roteiro ideal, verificando sua potencialidade em minimizar atos desvantajosos e maximizar aqueles vantajosos anteriormente tomados pelas empresas.

O estudo de dois casos foi desenvolvido em PME que participaram da primeira fase do trabalho de campo. A seleção dessas empresas esteve vinculada à disposição da gerência do projeto em contribuir para que todas as informações necessárias fossem obtidas e ao interesse de ambas pelo objeto de estudo desta investigação.

Todas as PME participantes da primeira fase foram contatadas e apenas as duas selecionadas se disponibilizaram a continuar participando do estudo. Os motivos alegados pelas demais variaram entre: falta de tempo do entrevistado, e mudança do profissional da área de informática, responsável pela adoção e implantação do sistema integrado. O Quadro 3 caracteriza as organizações envolvidas, denominadas de empresas A e B, diante da exigência de que seus nomes não fossem divulgados.

A coleta de informações, nesta segunda fase do trabalho de campo, foi conduzida com auxílio do roteiro ideal apresentado na seção anterior. O Quadro 4 sintetiza todas as atividades do roteiro ideal, comparando as empresas A e B de acordo com a realização, ou não, das etapas previstas no roteiro. Os detalhes explicativos em

Quadro 3. Caracterização das empresas estudadas.

\begin{tabular}{cclc}
\hline Empresa & Setor & Ramo de atuação & Faturamento (R\$) \\
\hline A & Industrial & Metalúrgico & 40 milhões \\
B & Serviços & $\begin{array}{l}\text { Administradora de } \\
\text { consórcio }\end{array}$ & 23 milhões \\
\hline
\end{tabular}


Quadro 4. Etapas do roteiro ideal e sua execução pelas empresas.

\begin{tabular}{|c|c|c|}
\hline Roteiro ideal & Empresa A & Empresa B \\
\hline \multicolumn{3}{|c|}{ Parte A - avaliação necessidade do ERP } \\
\hline Etapa 1 - análise situação atual & Superficial & Superficial \\
\hline $\begin{array}{l}\text { Etapa } 2 \text { - análise conceitual do } \\
\text { ERP }\end{array}$ & Não & Não \\
\hline $\begin{array}{l}\text { Etapa } 3 \text { - análise do ERP como } \\
\text { solução }\end{array}$ & Não & Não \\
\hline \multicolumn{3}{|c|}{ Parte B - seleção e adequação } \\
\hline $\begin{array}{l}\text { Etapa } 4 \text { - análise dos processos da } \\
\text { empresa }\end{array}$ & Não & Não \\
\hline Etapa 5 - seleção do sistema & Parcial & Parcial \\
\hline Etapa 6 - adequação & Parcial & Não \\
\hline Etapa 7 - análise do custo & Parcial & Parcial \\
\hline \multicolumn{3}{|c|}{ Parte C - implantação } \\
\hline $\begin{array}{l}\text { Etapa } 8 \text { - definição equipe } \\
\text { implantação }\end{array}$ & Parcial & Parcial \\
\hline $\begin{array}{l}\text { Etapa } 9 \text { - planejamento atividades } \\
\text { implantação }\end{array}$ & Parcial & Parcial \\
\hline $\begin{array}{l}\text { Etapa } 10 \text { - implantação dos } \\
\text { módulos ERP }\end{array}$ & Não & Sim \\
\hline
\end{tabular}

\begin{tabular}{|c|c|c|}
\hline \multicolumn{3}{|c|}{ Parte D - conscientização e treinamento } \\
\hline $\begin{array}{l}\text { Etapa } 11 \text { - palestras e seminários } \\
\text { de conscientização }\end{array}$ & Parcial & Parcial \\
\hline Etapa 12 - treinamento gerencial & Não & Sim \\
\hline Etapa 13 - treinamento operacional & Não & Sim \\
\hline \multicolumn{3}{|c|}{ Parte E - utilização } \\
\hline $\begin{array}{l}\text { Etapa } 14 \text { - identificação } \\
\text { modificações no sistema }\end{array}$ & Não & Não \\
\hline Etapa 15 - feedback & Não & Não \\
\hline
\end{tabular}

cada uma das situações estudadas são comentados após o quadro.

Etapa 1 - análise da situação atual: pode-se afirmar que, nas duas empresas, a análise foi superficial, pois ambas se encontravam pressionadas pelo bug do milênio e estavam diante de duas alternativas em relação aos seus sistemas de informação: preparar os sistemas legados para enfrentarem o bug ou partirem para uma nova solução, promovendo um salto tecnológico. Nos dois casos um novo sistema foi adquirido para suportar as atividades rotineiras de escritório. As atividades específicas, o core business das empresas, eram suportadas por sistemas específicos, desenvolvidos internamente, e tais sistemas foram integrados ao sistema de gestão adquirido.

Etapa 2 - análise conceitual do ERP: não foi realizada nos dois casos. Foram considerados somente os aspectos técnicos do sistema, como a existência de uma única base de dados. O sistema não foi analisado, nas situações estudadas, como uma ferramenta capaz de apoiar decisões gerenciais, e sim como um sistema de informação integrado, com capacidade para promover a integração da informação e suportar todas as áreas da empresa.
Como conseqüência da não realização da etapa 2, não foi executado um confronto conceitual do sistema em relação aos aspectos positivos e negativos da empresa, previsto pela etapa 3 .

Etapa 3 - análise do ERP como solução: durante toda a atividade de análise promovida pelas duas empresas, o aspecto considerado foi a capacidade técnica do sistema em solucionar o problema da falta de integração entre os sistemas de informação instalados. Em nenhum momento, o sistema foi considerado como um agente capaz de prover mudanças significativas nos processos de negócio executados.

Etapa 4 - análise dos processos da empresa: podese afirmar que nenhuma das duas empresas realizou uma revisão em seus processos de negócio. Ambas partiram da premissa que iriam se adequar aos processos implementados no sistema.

Etapa 5 - seleção do sistema: foi realizada parcialmente pelas duas empresas, pois analisaram poucas soluções dessa natureza. Excluíram, sem análise de aspectos técnicos e funcionais, algumas soluções disponíveis e muito difundidas na época devido aos custos proibitivos e se voltaram para uma solução destinada ao segmento das PME. Ao serem questionadas pela opção feita, justificaram pelas boas informações sobre a empresa fornecedora.

Etapa 6 - adequação: as adequações foram realizadas parcialmente somente na empresa A; parcialmente porque esta permitiu que, durante a atividade de implantação, fossem realizadas pequenas modificações no sistema mediante as solicitações dos usuários. Porém, quando percebeu que as modificações estavam fora do escopo inicial do projeto e contribuindo para encarecê-lo, além de atrasar a implantação do sistema, o gerente de projeto passou a analisar, rigorosamente, as solicitações para modificações no sistema, autorizando-as ou não. $\mathrm{Na}$ empresa $\mathrm{B}$ o escopo inicial do projeto foi seguido, e nenhum tipo de modificação foi realizada.

Etapa 7 - análise de custo: foi realizada de forma mais rigorosa na empresa $\mathrm{B}$. Nessa empresa não foi permitida nenhuma customização, justamente porque o gerente de projeto julgou que iria perder o controle sobre os custos envolvidos, justificando assim a rígida postura em relação à realização das modificações no sistema. Já na empresa $\mathrm{A}$, os aspectos financeiros referentes às customizações não foram considerados adequadamente, conforme foi abordado no parágrafo anterior. Um aspecto previsto no roteiro, e não considerado pelas duas empresas na fase inicial do projeto se refere aos custos referentes às atividades pós-implantação do sistema.

Etapa 8 - definição da equipe de implantação: a formação da equipe responsável pela implantação ocorreu de forma distinta nas duas empresas. Ambas se constituíram com dois gerentes de projeto, sendo um contratado 
da fornecedora do sistema (gerente de projeto externo) e outro funcionário da empresa, com cargo de gerência, denominado gerente de projeto interno. Da fornecedora do ERP também foi contratado um consultor técnico, responsável pela implantação do sistema. O gerente de projeto externo não era exclusivo, isto é, não esteve alocado integralmente e exclusivamente nas empresas. Sua função consistia em acompanhar o projeto, através de reuniões e visitas periódicas, e participar das decisões críticas. Os gerentes de projeto interno apresentaram perfis diferentes. A empresa A optou pelo perfil técnico e nomeou seu gerente de informática; e a empresa B decidiu por um profissional com perfil de negócios. Além desses membros, a empresa A incluiu em sua equipe de implantação dois programadores, funcionários internos, que atuaram em conjunto com o consultor técnico da fornecedora, instalando o sistema.

Etapa 9 - planejamento das atividades de implantação: pode-se dizer que como a empresa A não definiu adequadamente o escopo do projeto, observou-se que modificações não previstas foram realizadas no transcorrer da implantação, por solicitação dos usuários, incorrendo a um prazo maior de implantação do que o prazo planejado inicialmente. Na empresa B, o escopo foi delimitado, nenhuma customização no sistema foi permitida, e as implantações seguiram como previsto, ressalva feita somente para a duração do projeto. Aliás, nos dois casos estudados, observou-se que o cronograma previsto para implantação, apresentado pela fornecedora do sistema integrado sofreu uma revisão completa, pois os prazos foram subestimados. Os impactos, em relação à duração da implantação, não foram expressivos, pois os gerentes de projeto interno das duas empresas eram pessoas experientes e detectaram o problema no início. $\mathrm{O}$ impacto maior, expressado pelos dois gerentes internos, ocorreu em relação aos custos do projeto, bem superiores aos estimados inicialmente.

Etapa 10 - implantação dos módulos do sistema: prevê a parametrização e/ou customização de acordo com a etapa 6 - adequação. Nos casos estudados, as situações encontradas durante a Implantação foram decorrentes de problemas não tratados pela etapa 6 - adequação, conforme pode ser observado a seguir. Na empresa B, o sistema foi implantado sem a realização de nenhuma customização, e a empresa se adaptou integralmente ao modus operandi previsto no sistema. Na empresa A, foram realizadas modificações solicitadas pelo usuário no instante da implantação, sem planejamento anterior (previsto pela etapa 6). Observa-se que as empresas A e $\mathrm{B}$ apresentaram posturas conflitantes em relação à participação do usuário, porém as duas detinham a mesma opinião sobre as conseqüências de envolvê-los na implantação. Segundo análise das empresas, o usuário com a visão focada em suas atividades, atém-se a detalhes que, na concepção da gerência interna do projeto, podem comprometer todo o processo de implantação, implicando prazos maiores e custos acima dos previstos. Em relação à realização de modificações no sistema, as duas organizações se posicionaram favoráveis à adequação ao mesmo, desconsiderando as exigências e críticas dos usuários. A empresa B sustentou, durante toda a implantação, a postura inflexível de não executar quaisquer alterações no sistema. A empresa $\mathrm{A}$ cedeu à pressão dos usuários e realizou pequenas modificações, incorrendo em um prazo maior de implantação do que o planejado, mas sem grandes impactos no custo e prazo final para conclusão do projeto. Tal situação, verificada nas duas empresas, foi decorrente da forma como o usuário final foi envolvido no processo de implantação. A empresa A atribuiu ao usuário a responsabilidade pela transferência de informações necessárias ao profissional da implantação. A empresa B impediu esse contato, ficando a transferência de informações sob a responsabilidade do gerente interno do projeto.

Etapa 11 - palestras e seminários de conscientização: prevê a realização de atividades que esclareçam sobre o sistema, as mudanças introduzidas, a importância organizacional implicações sobre má utilização, relevância do papel dos envolvidos. Essas atividades foram conduzidas de forma distinta. Na empresa A, foram realizadas palestras para a diretoria e para o gerente da área de informática, não sendo realizados seminários de conscientização sobre a importância organizacional e implicações sobre má utilização. O enfoque das palestras foi tecnológico e não organizacional. Na empresa B realizaram várias palestras e seminários de conscientização para todos os funcionários, usuários do sistema. $\mathrm{O}$ enfoque das atividades foi tecnológico, com pequena abordagem organizacional sobre implicações da não atualização dos dados e sobre a facilidade ao acesso de informação das outras áreas da empresa.

Etapa 12 - treinamento gerencial e etapa 13 - treinamento operacional: contemplam o aspecto organizacional e operacional. A realização da etapa 12 visa suprir a alta administração com informações sobre uso e manuseio do sistema que irão auxiliar a gestão da organização, sem foco operacional. Essa etapa foi conduzida somente na empresa B. Percebeu-se que o treinamento teve caráter distinto nas duas empresas e isso pode ser compreendido ao observar o perfil da gerência interna do projeto. Na empresa $\mathrm{A}$, a gerência pertencia à área de informática e considerou o treinamento desnecessário, pois partiu da premissa que o sistema era amigável, e técnicos e usuários não teriam grandes dificuldades. Para a gerência interna do projeto da empresa $\mathrm{B}$, pertencente à área de negócios, o treinamento foi priorizado, sendo realizadas atividades de treinamento e de conscientização para todos os usuários envolvidos. 
Etapa 14 - identificação de modificações no sistema e a etapa 15 - feedback: não foram realizadas por nenhuma das duas empresas, porque ambas, no momento do estudo, haviam acabado de concluir a implantação, não havendo tempo hábil para avaliação das necessidades de modificações.

Em relação à aplicação dos roteiros, a avaliação dos dois gerentes de projetos quanto ao uso do roteiro ideal foi muito positiva. Ambos destacaram o fato do roteiro permitir uma visão geral das etapas necessárias à adoção do sistema. Essa visibilidade permite o planejamento para situações críticas que podem ocorrer durante a implantação.

Outro aspecto positivo do roteiro ideal se refere ao fato dele considerar pontos que, normalmente os fornecedores não discutem, como, por exemplo, as atividades previstas na etapa 1 - análise da situação atual, em que a empresa faz uma análise interna e verifica seus problemas e potencialidades, sem considerar ainda a adoção de um sistema.

Por fim, nas duas empresas estudadas, os dois gerentes de projeto ressaltaram um aspecto extremamente positivo do roteiro, que é a isenção diante do forte marketing dos vendedores de sistemas integrados de gestão.

\section{Considerações finais}

Como as grandes organizações, as PME também buscam técnicas e ferramentas de modernização adequadas às suas particularidades, que garantam a sua atuação numa economia globalizada. Porém as PME esbarram em uma dificuldade: suas limitações financeiras. Além disso, as singularidades dessas organizações, em relação às grandes empresas, lhes conferem padrões diferenciados, que necessitam ser observados no contexto destas especificidades. Ao investir em tecnologia, as PME são cautelosas, pois reconhecem suas limitações financeiras e humanas.

A grande motivação para a aquisição de sistemas ERP pelas PME, passado o problema do bug do milênio, é a demanda para aquisição de um sistema de informação que permita a integração dos processos executados pelas diversas áreas da empresa, garantindo a confiabilidade e a facilidade de acesso às informações armazenadas.

Diante das particularidades observadas, foi proposto o roteiro ideal com a finalidade de auxiliar as PME a conduzirem o processo de mudança no qual se vêem envolvidas quando optam pela adoção de sistemas integrados. O roteiro prevê etapas que ajudam os agentes de mudança a gerenciarem o processo de adoção de sistemas ERP. Através do roteiro é possível visualizar todo o processo de mudança pelo qual as PME passarão e não perder o foco da transformação que será conduzida.
Sem este auxílio, as PME sentem necessidade de recorrer ao serviço de uma consultoria para gerenciar o projeto.

Como sugestão para adoção de sistemas ERP pelas PME, uma alternativa seria a adoção gradual, minimizando assim as mudanças a serem realizadas e parcelando o investimento necessário. É necessário lembrar, que o roteiro ideal pode ser aplicado várias vezes, e cada aplicação refere-se a um ciclo do processo de implantação. Assim, no primeiro ciclo de aplicação do roteiro, as PME adquirem o sistema sem realizar nenhuma adequação ou modificação no mesmo; se estas forem imprescindíveis, devem ser as menores possíveis. Neste contexto podem ser adquiridos, primeiramente, os módulos do sistema que suportam as atividades rotineiras existentes em qualquer organização, como as contábeis e financeiras, por exemplo. Os módulos são implantados em sua versão original, os funcionários são treinados nesses módulos, aprendendo a trabalhar de acordo com o sistema. Conduzindo o processo desta maneira, as PME têm condições de garantir que o ERP seja implantando no tempo previsto e conforme os custos estipulados inicialmente. Durante o primeiro ciclo de aplicação do roteiro elas obtêm conhecimento sobre a tecnologia adquirida.

No segundo ciclo, as PME atendem às solicitações de modificações dos usuários familiarizados com o ERP, e iniciam o processo de adaptação do sistema à sua forma de trabalho. Neste ponto as PME já adquiriram conhecimento sobre o sistema, suas potencialidades e limitações, e passam a ter condições de negociar de forma sustentada com a fornecedora do sistema, as modificações a serem feitas, o tempo necessário para o seu processamento e o custo da operação.

No terceiro ciclo, as PME devem considerar o sistema ERP como suporte às suas atividades de negócio propriamente ditas. São nessas atividades que residem as particularidades ou especificidades das PME. Tendo passado pelos dois primeiros ciclos de utilização do roteiro, o suporte às atividades rotineiras e administrativas presentes em toda empresa estará funcionando adequadamente, sendo necessário então adequar o ERP para que apóie as atividades de negócio, ou seja, as atividades específicas. A cada ciclo, as PME minimizam a resistência dos funcionários, de modo que, no momento de implementarem as mudanças mais críticas, eles já estão habituados a esta tecnologia.

Conclui-se, após o estudo realizado, que o roteiro ideal é eficiente e útil neste segmento empresarial, uma vez que apresenta uma visão completa do processo de análise e adoção do ERP nas PME e o ilustra, não deixando de prover orientação em todas as etapas deste processo. Por sua imparcialidade, representa uma contribuição de fácil aplicação, para auxiliar o segmento das PME na adoção de sistemas ERP. O uso do roteiro norteia e converge os esforços destas empresas para garantir que os altos inves- 
timentos feitos tragam os benefícios esperados e atendam as suas expectativas.

A limitação do roteiro ideal está relacionada à ausência de sua validação no segmento das PME. A aplicação integral do roteiro ideal, concomitante ao processo de adoção do sistema por uma empresa, possibilitaria a identificação de atividades não previstas e a proposição de ferramentas a serem usadas em algumas de suas etapas, como: o desenvolvimento de planilhas específicas visando a seleção e comparação dos sistemas ERP, a análise do fornecedor e o cálculo do custo do projeto. Para a análise dos processos das PME, poder-se-ia propor a utilização de um pequeno roteiro que as auxiliasse a conduzir esta análise de forma padronizada. A aplicação do roteiro ideal em uma amostra com apenas duas PME não garante sua validação, porém norteou quanto à adequação de sua utilização e indicou a possibilidade de trabalhos futuros.

\title{
Technological innovation in small and medium sized enterprises: proposal of a plan to acquire enterprise resource planning systems (ERP)
}

\begin{abstract}
The aim of this article is to show the results of research carried out in order to develop and validate an Ideal Plan to acquire Enterprise Resource Planning systems (ERP) concerning the characteristics of small and medium sized enterprises (SME). The Plan offers an overview of the steps a firm should follow in the process of adopting ERP, and guides, not the selection of the system or supplier, but the evaluation of the appropriateness and the impacts in organizational changes. These changes are not secondary neither peripherical to adopting ERP, but in fact, define the system's potential operation and, as a result the efficacy of the acquisition. The field research was carried out in two steps: the first one investigated ten companies, after a bibliography review regarding adopting the information technology models; this step was useful to adjust the theoretical concepts to the reality of SMEs. The second phase was done after the Ideal Plan was developed, with the proposal of validating it in two enterprises. The research has limitations, but the results are relevant due to the scarcity of appropriate literature concerning ERPs and SME. The model which was developed has proved to be more detailed than the enterprises' previous procedures and, therefore, it may be useful to SMEs in innovation technological phases.
\end{abstract}

Keywords: Enterprise resource planning. ERP. Small and medium enterprises.

\section{Referências bibliográficas}

CHUANG, M.; SHAW, W. H. A roadmap for e-business implementation, Engineering Management Journal, Rolla, v. 17, n. 2, p.3-14, jun. 2005.

COMPUTERWORLD. Uma Tropa de elite para tocar o negócio. Disponível em: <http://www.uol.com.br/computerworld/ 100maiores98/software/sof_12.htm>. Acesso em: $20 \mathrm{dez}$. 1999.

COOPER, R.; ZMUD, R. W. Information technology implementation research: a technological diffusion approach. Management Science, Providence, v. 36, n. 2, p. 123-139, feb. 1990.

CORRÊA, H. C. ERP's: por que as implantações são tão caras e raramente dão certo? In: SIMPÓSIO DE ADMINISTRAÇÃO DA PRODUÇÃO, LOGÍSTICA E OPERAÇÕES
INDUSTRIAIS, 1., 1998, São Paulo. Anais... São Paulo: FGV. 1998. p. 288-300.

CORRÊA, H. C.; DIAS, G. P. P. De volta a gestão de estoques: as técnicas estão sendo usadas pelas empresas? In: SIMPÓSIO DE ADMINISTRAÇÃO DA PRODUÇÃO, LOGÍSTICA E OPERAÇÕES INDUSTRIAIS, 1., 1998, São Paulo. Anais... São Paulo: FGV. 1998.

CORREAA, H. C.; GIANESI, I.; CAON, M. Planejamento, programação e controle da produção: MRP II/ ERP: conceitos, uso e implantação. 4. ed. São Paulo: Atlas, 1997. $449 \mathrm{p}$.

CUNHA, M. A. L. Gestão integrada de processos de negócio. In: SIMPÓSIO DE ADMINISTRAÇÃO DA PRODUÇÃO, 
LOGÍSTICA E OPERAÇÕES INDUSTRIAIS, I.,1998, São Paulo. Anais... São Paulo: FGV. p.184-194.

DAVENPORT. T. H. Putting the enterprise into the enterprise system. Harvard Business Review, Boston, v. 76, n. 4, p. 121-131. Jul.-Aug. 1998.

FERREIRA, A. B. de H. Novo dicionário da língua portuguesa, Rio de Janeiro: Nova fronteira, 1975.

FIRMINO, M. Por que a pequena empresa resiste à tecnologia. Web Insider, abr. 2003. Disponível em: <http://webinsider.uol. com.br>. Acesso em: 27 out. 2003.

GREMBA, J.; MYERS, C. The Ideal process model: a practical guide for improvement, 1998. Disponível em: <http://www.ser. cmu.edu/activities/idel/ideal.bridge.html $>$. Acesso em: 5 feb. 2002.

GUPTA, O.; PRIYADARSHINI, K.; MASSOUD, S.; AGRAWAL, S. Enterprise resource planning: a case of blood bank. Industrial Management \& Data Systems, v. 104, n. 7, p. 589, 2004.

HUANG, A.; YEN, D. C.; CHOU, D. C.; XU, Y. Corporate applications integration: challenges, opportunities, and implementation strategies. Journal of Business and Management, v. 9, n. 2, p. 137-150, spring, 2003.

KRUGLIANSKAS, I. Tornando a pequena e média empresa competitiva. São Paulo: IEGE, 1996. 137 p.

LEE, J.; SIAU, K.; HONG, S. Enterprise integration with ERP and EAI. Association for Computing Machinery, New York, v. 46, n. 2, p. 54, fev. 2003.

MCGEE, J.; PRUZAK, L. Gerenciamento estratégico da informação. Rio de Janeiro: Campus. 1997. 244 p.

SIAU, K. Enterprise resource planning (ERP) implementation methodologies. Journal of Database Management, v. 15, n. 1, p. I. jan-mar. 2004.

SIAU, K.; TIAN, Y. Supply Chains integration: architecture and enabling technologies. The Journal of Computer Information Systems, Stillwater, v. 44, n. 3, p. 67- 73 spring, 2004.
SILVA, J. F. et al. Transferência de tecnologia e sistemas integrados. In: SIMPÓSIO DE GESTÃO DA INOVAÇÃO TECNOLÓGICA, 20., 1998, São Paulo. Anais... São Paulo: TecArt. 1998. 1 CD-ROM.

SOUZA, C. A. Sistemas integrados de gestão empresarial: estudos de casos de implementação de sistemas ERP. 2000. Dissertação (Mestrado em Administração) - Faculdade de Economia e Administração, Universidade de São Paulo, São Paulo, 2000.

SOUZA, C.A.; ZWICKER, R. Ciclo de vida de sistemas ERP. São Paulo, v. 1, n. 11, jan./mar, 2000. (Caderno de pesquisas em administração).

STAMFORD, P. P. ERP's: prepare-se para esta mudança. 2000. Disponível em: <http://www.kmpress.com.br/00set02.htm>. Acesso em: 13 set. 2000.

TARN, J. M.; YEN, D. C. Y.; BEAUMONT, M. Exploring the rationales for ERP and SCM integration. Industrial Managemet \& Data Systems, v. 102, n. 1/2, p. 26-34, 2002.

TAURION, C. Oportunidades e riscos na escolha de uma solução ERP. Computerworld, 1999. Disponível em: <http://www. uol.com.br/computerworld/computerworld/280/gcapa3.htm>. Acesso em: 24 set. 1999.

ZWICKER, R.; SOUZA, C. A. Sistemas ERP: conceituação, ciclo de vida e estudos de casos comparados. In: SOUZA, C.A.; SACCOL, A. Z. (org.). Sistemas ERP no Brasil. São Paulo: Atlas, 2003. p-63-87.

WANG, M.; ZHANG, S. Integration EDI with an E-SCM system using EAI technology. Information Systems Management, Boston, v. 22, n. 3, p. 31-37, summer, 2005.

WEBER, M. Economia e Sociedade. Brasília, DF: Editora da Universidade de Brasília, 1991. v. 1.

WOOD Jr., T. Modas e modismos gerenciais: o caso dos sistemas integrados de gestão. São Paulo: FGV, n. 16, 1999. 77 p. (Série de Relatórios de Pesquisa, NPP - Núcleo de Pesquisas e Publicações).

\section{Sobre os autores}

\section{Juliana Veiga Mendes}

Engenharia de Produção, Universidade Federal de São Carlos - UFSCar, Campus Sorocaba, Avenida Darci Carvalho Dafferner, 200, CEP 18043-970, Alto da Boa Vista, Sorocaba, SP, Brasil, e-mail: juveiga@ufscar.br

\section{Edmundo Escrivão Filho}

Escola de Engenharia de São Carlos, Departamento de Engenharia de Produção, Universidade de São Paulo - USP, Av. Trabalhador São-carlense, 400, Centro, CEP 13566-590, CP 359, São Carlos, SP, Brasil, e-mail: edesfi@sc.usp.br 
